\title{
PERANCANGAN GENERATOR LOW RPM UNTUK PLTAngin
}

\author{
SP Mursid \\ Jurusan Teknik Konversi Energi - Politeknik Negeri Bandung \\ E-mail: sp_mursid@yahoo.co.id
}

\begin{abstract}
Abstrak
Pemanfaatan angin sebagai sumber energi terbarukan berpeluang untuk memberikan solusi murah dalam pengadaan energi listrik bagi masyarakat. Namun demikian, dikarenakan rata-rata kecepatan angin di Indonesia, khususnya di Bandung relatif rendah, maka perlu dibuat mesin pengkonversi putaran rendah ke energi listrik yang efesien. Generator Low RPM (Revolution Per Minute) dapat memberikan jawaban pada persoalan konversi ini. Saat ini masih sulit mendapatkan generator Low RPM di pasaran Indonesia. Jikapun ada, harganya sangat mahal. Oleh karenanya, merancang dan membangun sendiri generator Low RPM akan dapat menjadi alternatif pengadaanya.
\end{abstract}

Kata kunci: energi terbarukan, PLT Angin, generator, low RPM.

\begin{abstract}
Absract
Utilization of wind power as a renewable energy source has an opportunity to provide low-cost solutions in the supply scheme of electric energy for the community. However, do to the low average wind speed in Indonesia, especially in Bandung, it needs to design low speed converting machines that can convert efficiently low rpm (revolution per mimute) of shaft speed into electrical energy. Low rpm generator can provide answers to the issue of this conversion. But we knew this is still difficult to obtain low rpm generator in Indonesian market. Even if there are available in the market, the price is very expensive. Therefore, to design and build our own low rpm generators will be able to be an alternative solution.
\end{abstract}

Key words: renewable energy, wind power, generator, low rpm

\section{PENDAHULUAN}

Pembangkit Listrik Tenaga Angin (PLT-Angin) dapat memberikan peluang untuk mendapatkan energi alternatif selain dari minyak bumi dengan mengkonversi-kan energi angin ke energi listrik. Energi yang dikonversikan ke listrik akan sesuai dengan potensi energi angin dikalikan dengan efesienși PLT-Angin $\left(E_{\text {listrik }}=E_{\text {potangin }} x \eta\right)$.

Energi yang dapat diperoleh dari angin merupakan perbandingan langsung dari fluks angin yakni : $E_{\text {angin }}=1 / 2 \rho V o^{3} A$ (Watt). Rho $(\rho)$ merupakan masa jenis dari angin yang berubah berdasarkan ketinggian dari permukaan laut. Umumnya akan berharga $\rho=1,225 \mathrm{~kg} / \mathrm{m} 3$. Dalam kalkulasi praktir, Rho $(\rho)$ akan diambil pada harga $\rho=1,0 \mathrm{~kg} / \mathrm{m}^{3}$. Sangat jelas dari persamaan energi angin, bahwa kecepatan angin $V_{\infty} \infty$ sangat berpengaruh terhadap besarnya energi yang dihasilkan. Karena energi yang dihasilkan akan sebanding dengan kecepatan dan torsi poros, maka kecepatan poros sendiri akan sangat sensitif terhadap perubahan kecepatan angin. Kecepatan poros turbin akan melonjak pangkat tiga terhadap kecepatan angin.

Di sisi lain, turbin angin sebagai konverter energi angin ke putaran poros tergolong mesin yang berputar pada rpm (revolution per minute) rendah. Ini artinya dibutuhkan generator listrik rpm rendah yang mampu mengkonversikan putaran rendah poros ke energi listrik dengan tegangan kerja normal.

Teknologi PLT-Angin berkembang pesat khususnya di negara maju seperti Denmark dan Swedia. Turbin angin dengan skala di atas 25 MW sudah lumrah dipasang untuk memproduksi listrik bagi masyarakat di sebagian negera Eropa. Sayangnya Indonesia tergolong tertinggal dalam bidang PLT-Angin. Diduga hal ini 
dikarenakan energi konvensional masih mudah diperoleh dan murah, sehingga usaha untuk memanfaatkan energi alternatif khususnya angin masih belum optimal, bahkan belum diperhitungkan. Indonesia, dengan kontur pantai dan daerah pegunungan yang kaya, sesungguhnya memiliki potensi energi angin berlimpah. Jika memperhitungkan seluruh potensi maka ada $73 \mathrm{GW}$, dan dengan memperhitungkan teknologi yang ada saat ini diperoleh kapasitas terpasang optimum $=25$ MW, namun kapasitas saat ini baru 0,6 MW.

Pada skala kecil, di bawah 2000 watt, turbin pada PLT-Angin dapat dibuat dengan mudah bahkan oleh konstruktor amatir. Penelitian PLTAngin skala kecil telah dilakukan untuk melihat peluang pembangkitan energi listrik di rumahrumah penduduk yang dapat dikonstruksi secara mudah dan mandiri. Penelitian sebagaimana dimaksud di atas telah penulis lakukan pada tahun 2008 dengan didanai oleh Hibah Penelitian Politeknik Negeri Bandung (Polban). Penelitian dengan judul Pembuatan Prototipe PLT-Angin Domestik juga merupakan rangkaian dan kelanjutan dari penelitian kami sebelumnya yang berjudul Energi Listrik Alternatif Menggunakan PLT-Hibrida pada RUT VII. Terakhir, penelitian yang dilakukan yang mengait pada topik bahasan ini berjudul Auto Brake Generator PLT-Angin, yang didanai oleh Hibah Kompetitif Penelitian Sesuai Prioritas Nasional.

Rangkaian penelitian yang telah dilakukan mengantarkan pada kesimpulan sementara bahwa bagian kritis dari PLT-Agin adalah pada generator dan sistem pengatur kecepatan poros. Generator harus mampu menghasilkan daya listrik pada kecepatan rendah untuk mendapatkan konversi energi paling efesien, sedangkan sistem pengatur kecepatan akan menjaga turbin dan poros berputar pada kecepatan aman. Jika tersedia perangkat yang dapat berfungsi sebagi generator rpm rendah sekaligus berfungsi sebagai speed regulator, maka PLT-Angin menjadi sangat mudah dibangun dan berpeluang menjadi sumber energi listrik altenatif yang dapat dimiliki oleh siapa saja sejauh di tempat tersebut tersedia potensi energi angin yang mencukupi.

\section{MODEL GENERATOR}

Generator sebagai pengkonversi energi mekanik putaran poros menjadi energi listrik memanfaatkan fenomena elektromagnetik yang menghubungkan torsi, medan magnet dan arus listrik. Generator dapat dibuat dengan menggunakan motor DC yang telah dilengkapi dengan magnet permanen. Persamaan sederhana pada konversi DC, $F=I L B$ dimana $F$ merepresentasikan daya, I arus listrik, L identik dengan luas konduktor pada generator yang terpapar medan magnet dan B merupakan kuat medan dapat memberikan gambaran akan relasi medan magnet dengan besarnya daya.

Keberhasilan dari rancangan generator ${ }^{\bullet}$ yang akan dibuat menekankan pada kesederhanaan dan kekuatan konstruksi. Oleh karenanya dihindari untuk membuat generator yang membutuhkan arus eksitasi pembangkit medan magnet. Generator dengan menggunakan magnet permanen dipilih untuk alasan kesederhanaan konstuksi dan keandalan. Keuntungan menggunakan magnet permanen adalah tidak diperlukannya energi awal untuk mencatu arus eksitasi, hal ini cocok dengan karakteristik dari PLT-Angin yang umumnya diinstalasikan di daerah terpencil.

Generator dengan magnet permanen memudahkan untuk mendapatkan rancangan generator rpm rendah. Kecepatan putar generator (rpm) berkorelasi dengan jumlah pole magnet yang dipergunakan. Persamaan berikut menggambarkan hubungan yang dimaksudkan.

$\mathrm{rpm}=\frac{\text { frekwensi }}{\text { pole } / 2}$

Dari persamaan terlihat bahwa jumlah pole berbanding terbalik dengan rpm generator. Semakin banyak pole yang dipergunakan, akan diperoleh generator dengan rpm semakin rendah.

\section{KONSEP GENERATOR LOW RPM}

Generator merupakan perangkat mesin listrik yang mengubah energi kinetik atau energi gerak menjadi energi listrik. Umumnya energi gerak merupakan gerakan berputar yang memiliki kecepatan angular tertentu. Konversi energi 
gerak menjadi listrik dimungkinkan dengan menerapkan hukum Faraday yang menyatakan bahwa jika ada konduktor yang mendapatkan paparan medan magnet yang berubah, maka pada konduktor tersebut akan mengalir arus listrik. Dengan pemahaman ini maka gerakan berputar dipergunakan untuk menggerakkan magnet permanen pada kumparan konduktor sehingga pada konduktor akan selalu mendapatkan medan magnet yang berubah. Secara sederhana skema generator dengan medan magnet berputar diperlihatkan pada Gambar 1 Skema Generator.

Pada Gambar Skema Generator terdapat magnet permanen yang dapat berputar pada sumbu tengahnya. L1 dan L2 merupakan kumparan konduktor yang dihubungkan secara seri, sehingga dari terminal A sampai B merupakan satu jalur arus listrik. Jika magnet digerakkan berputar pada sumbunya, maka kutub $\mathrm{S}$ (selatan) dan U (utara) akan bergerak sesuai dengan arah gerakan magnet, hal ini mengakibatkan medan magnetnya ikut berputar sehingga kumparan yang ada didekatnya akan terpotong oleh medan magnet yang berubah. Maka sesuai dengan hukum Faraday, pada terminal $\mathrm{AB}$ akan mengalir arus jika dibebani, dan pada terminal tersebut akan terjadi beda tegangan $\mathrm{V}_{\mathrm{ab}}$. Tegangan yang dihasilkan adalah tegangan $\mathrm{AC}$ (Alternating Current) dengan bentuk sinusoidal murni. Tegangan puncaknya akan terjadi pada saat pole magnet berada paling dekat dengan kumparan. Hal ini dapat disimpulkan bahwa semakin dekat kumparan terhadap medan magnet, maka akan dihasilkan tegangan lebih tinggi. Pengetahuan ini akan dipergunakan untuk membuat rancangan generator yang memungkinkan kumparan penghasil arus berada pada posisi terdekat dengan magnet.

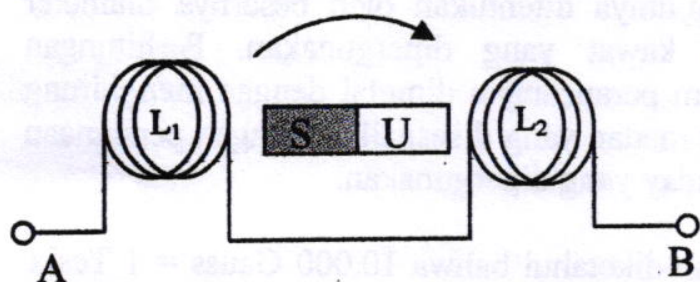

Gambar 1. Skema Generator

Tegangan pada kumparan juga dipengaruhi oleh kecepatan perubahan medan magnet yang memotongnya. Ini dapat diartikan semakin cepat magnet diputar pada porosnya, akan semakin cepat kutub utara dan kutub selatannya saling berganti, selanjutnya akan semakin besar tegangan yang dihasilkan pada kumparan. Aspek perubahan kutub magnet ini nantinya akan dipergunakan untuk merencanakan jumlah magnet yang dipergunkan dalam rancangan generator selanjutnya.

Secara umum generator akan memiliki komponen utama:

- Rotor yang merupakan komponen secara mekanis berputar untuk menggerakkan medan magnet;

- Stator tempat kumparan yang menerima perubahan medan magnet untuk dikonversi menjadi tegangan.

Jumlah kutub magnet pada rotor akan berpengaruh pada kecepatan putaran setiap menitnya $(R P M=$ Revolution Per Minute) untuk menghasilkan tegangan AC dengan frekwensi tertentu. Pada skema generator yang ditampilkan di atas, untuk menghasilkan frekwensi $50 \mathrm{~Hz}$ dengan 2 kutub $U$ dan $S$, diperlukan kecepatan $3000 \mathrm{rpm}$. Semakin banyak pole, akan semakin rendah putaran yang diperlukan. Secara umum persamaannya adalah sebagai berikut,

$$
\begin{array}{ll}
\mathrm{RPM}=\frac{120 \times f}{N} \\
\text { dengan } & \mathrm{f}=\text { frekwensi dari tegangan sinusoidal } \\
& \mathrm{N}=\text { jumlah kutub pada rotor }
\end{array}
$$

Sebagai misal, jika diharapkan frekwensi yang dihasilkan $50 \mathrm{~Hz}$, dengan 2 kutub, maka:

$\mathrm{RPM}=\frac{120 \times 50}{2}=3000$ putaran setiap menitnya. Tegangan yang dibangkitkan oleh generator mengikuti persamaan Faraday, atau juga persamaan gaya gerak listrik memberikan nilai tegangan pada kumparan stator generator sehingga memungkinkan arus listrik mengalir ke beban. Persamaan ini diturunkan dari Hukum Faraday bahwa: "emf = total fluks magnet yang dipotong tiap satuan waktu."

$V o=\frac{\varphi n Z}{60} \times \frac{P}{a}$ volt

dengan:

$$
\begin{array}{ll}
V o & =\text { gaya gerak listrik } \\
\varphi & =\text { fluks tiap kutub (Weber) } \\
\mathrm{p} & =\text { jumlah kutub } \\
\mathrm{n} & =\text { kecepatan putar rotor (rpm) } \\
\mathrm{Z} & =\text { jumlah konduktor jangkar }
\end{array}
$$




\section{a = jumlah lintasan paralel}

Daya yang dihasilkan oleh generator dipengaruhi oleh besarnya torsi yang diberikan pada rotor dan kemampuan kumparan stator (armatur) dalam menyalurkan arus listrik. Kemampuan menyaluran arus listrik pada kumparan berbanding lurus dengan besarnya diameter kawat yang dipergunakan.

\section{PERHITUNGAN DAYA GENERATOR}

Daya listrik yang dibangkitkan oleh generator akan sangat tergantung pada tegangan dan arus listrik yang dapat dibangkitkan generator saat bekerja. Variabel tegangan dan arus berkorelasi langsung dengan jumlah belitan pada stator, besarnya medar magnet pada rotor, jarak antara rotor dan stator, dan yang terpenting adalah kecepatan putar rotor dalam setiap menitnya (RPM) yang akan merepresentasikan perubahan medan magnet yang memotong kumparan stator.

Persamaan yang umum dipergunakan dalam mengestimasi perhitungan tegangan listrik terhadap medan magnet dan perubahan medan magnet dipergunakan persamaan Faraday. Persamaan umumnya adalah sebagai berikut,

Dengan:

$$
\mathrm{V}=-\mathrm{N}(\mathrm{B} \cdot \mathrm{A} / \mathrm{t}) \text {, }
$$

$$
\begin{aligned}
& \checkmark \quad \mathrm{V}= \text { tegangan yang dibangkitkan oleh } \\
& \text { generator; } \\
& \checkmark \quad \mathrm{N}= \text { Jumlah kumparan pada stator } \\
& \checkmark \mathrm{B}= \\
& \checkmark \quad \mathrm{Auat} \text { medan magnet pada rotor } \\
&= \text { luas dari kumparan yang terpapar } \\
& \text { oleh medan magnet } \\
& \checkmark \quad \mathrm{t}= \text { waktu yang diperlukan terjadinya } \\
& \text { perubahan medan magnet. }
\end{aligned}
$$

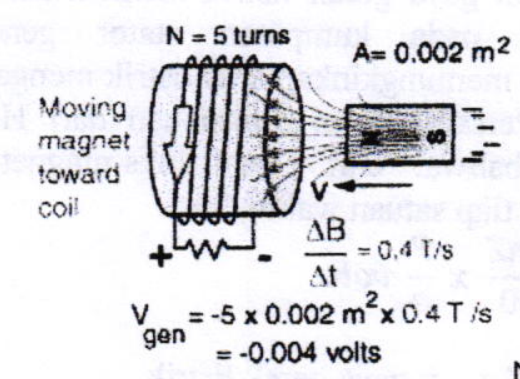

Gambar 2. Model Generator dengan Persamaan Faraday
Dari Gambar di atas dicontohkan stator dengan lima (5) lilitan seluas $\mathrm{A}=0,002 \mathrm{~m}^{2}$ yang didekatkan pada magnet dengan perubahan medan $0,4 \mathrm{~T} / \mathrm{s}$ akan diperoleh tegangan generator sebesar - 0,004 volt. Contoh di atas merupakan miniatur dari generator, namun pada rancangan selanjutnya akan dihitung nilai daya listrik genertor yang lebih besar.

Perancangan generator akan memiliki properti yakni kecepatan angin dianggap relatif rendah karena dipilih yang mungkin diperoleh di sekitar kampus Polban yakni berkisar antara 3 sampai 5 $\mathrm{m} /$ detik. Dengan kecepatan ini rancangan turbin yang telah dibuat pada Riset PLT-Angin domestik dapat memberikan kecepatan putaran sekitar 300 RPM yang merupakan kecepatan optimum rancangan. Dalam konstruksi generator akan dipergunakan magnet $\mathrm{NdFeb}$ atau Nyobdinium Iron Boron atau juga dikenal dengan magnet rare earth berukuran 50,8 x 25,4 $\mathrm{mm}^{2}$ dengan kuat magnet 10.000 gauss. Konstruksi magnet yang menempel pada rotor terhadap kumparan yang dipasang pada stator kurang lebih $2 \mathrm{~mm}$ yang merupakan jarak yang relatif renggang karena untuk menjaga agar tidak terjadi gesekan. Jarak sejauh ini akan mengakibatkan kuat medan magnet yang sampai ke kumparan menurun sekitar $30 \%$ sehingga kuat medan menjadi 7.000 gauss di dalam kumparan.

Rancangan generator diharapkan mampu menghasilkan tegangan listrik yang cukup untuk men-charge baterai 12 volt, sehingga diharapkan akan menghasilkan tegangan kerja 14 volt pada RPM nominal (300 RPM). Yang diperlukan selanjutnya adalah menghitung banyaknya belitan pada stator untuk menghasilkan tegangan yang dimaksud. Arus listrik yang dibangkitkan selanjutnya ditentukan oleh besarnya diameter dari kawat yang dipergunakan. Perhitungan dalam perancangan dimulai dengan menghitung kuat medan yang disesuaikan dengan persamaan Faraday yang dipergunakan.

Telah diketahui bahwa 10.000 Gauss $=1$ Tesla . Persamaan untuk mendapatkan jumlah belitan akan menjadi: $\quad N=-1 x-V(B x A / t)$

$$
\mathrm{N}=\mathrm{V} \times(\mathrm{B} \times \mathrm{A} / \mathrm{t})
$$

Diketahui bahwa luas dari magnet adalah: 
$A=50,8 \times 25,4 \mathrm{~mm}^{2}=0,001290,32 \mathrm{~m}^{2}$

Dengan kecepatan putar 300 RPM atau setiap putaran adalah 0,2 detik. Dengan demikian $\mathrm{N}=14 /(0,7 \times 0,00129 / 0,2)=3100$ belitan

Jika dalam rancangan generator dibuat 18 pole tiga fasa, maka setiap fasa akan terdiri dari 6 pole. Jadi setiap pole akan memerlukan belitan sebanyak Npole $=3100 / 6=516,67$ belitan. Masing masing belitan pada pole dibubungkan secara serial.

Jika dipilih kawat dengan diameter $0.8 \mathrm{~mm}$, maka generator mampu menangani arus sampai 25 ampere. Sehingga daya yang dapat dihasilkan pada kecepatan angin $5 \mathrm{~m} /$ detik kurang lebih adalah $25 \times 14 \times 3=1050$ watt.

\section{PEMILIHAN JUMLAH POLE STATOR}

Pemilihan jumlah pole atau kutub pada generator mempertimbangkan aspek berikut:

$\checkmark$ mendapatkan RPM serendah mungkin;

$\checkmark$ mengusahakan dimensi dari generator seringkas mungkin;

$\checkmark$ mempertimbangkan aspek kelancaran putaran khususnya pada saat start tidak terjadi kemacetan.

Dengan pertimbangan sebagaimana di sampaikan di atas, maka pemilihan jumlah kutub antar stator dan rotor tidak sama jumlahnya. Hal ini akan diterangkan pada akhir bahasan.
Pada stator dipilih jumlah pole sebanyak 22, artinya terdapat 11 pasangan magnet dengan kutub berlawanan (N dan $\mathrm{S}$ ). Jika kecepatan nominal yang diinginkan adalah $300 \mathrm{RPM}$, maka

- Terdapat 300 RPM/60 $=5$ Putaran Perdetik

- Maka satu kutub pada pada stator yang dililiti kumparan akan mendapatkan perubahan medan magnet $\mathrm{N}$ ke $\mathrm{S}$ atau sebaliknya dalam satu detik adalah perubahan Medan Magnet Pole Stator $=5 \mathrm{x}$ $11=55$ kali. Ini artinya akan menghasilkan frekwensi listrik 55 Hertz.

Frekwensi ini dapat dipandang sebagai frekwensi nominal yang mendekati frekwensi grid PLN. Walaupun demikian, ketepatan frekwensi bukan tujuan utama karena tegangan yang dihasilkan oleh generator nantinya akan disearahkan menjadi tegangan DC yang dapat disimpan dalam baterai.

Pole pada stator dipilih hanya 18 kutub dengan mempertimbangkan bahwa generator dapat disusun secara 3 fasa. Susunan tiga fasa memiliki keuntungan:

$\checkmark$ mudah disearahkan menjadi tegangan DC yang rata;

$\checkmark$ meningkatkan kemampuan handling arus listrik, sehingga dihasilkan daya listik generator yang lebih besar;

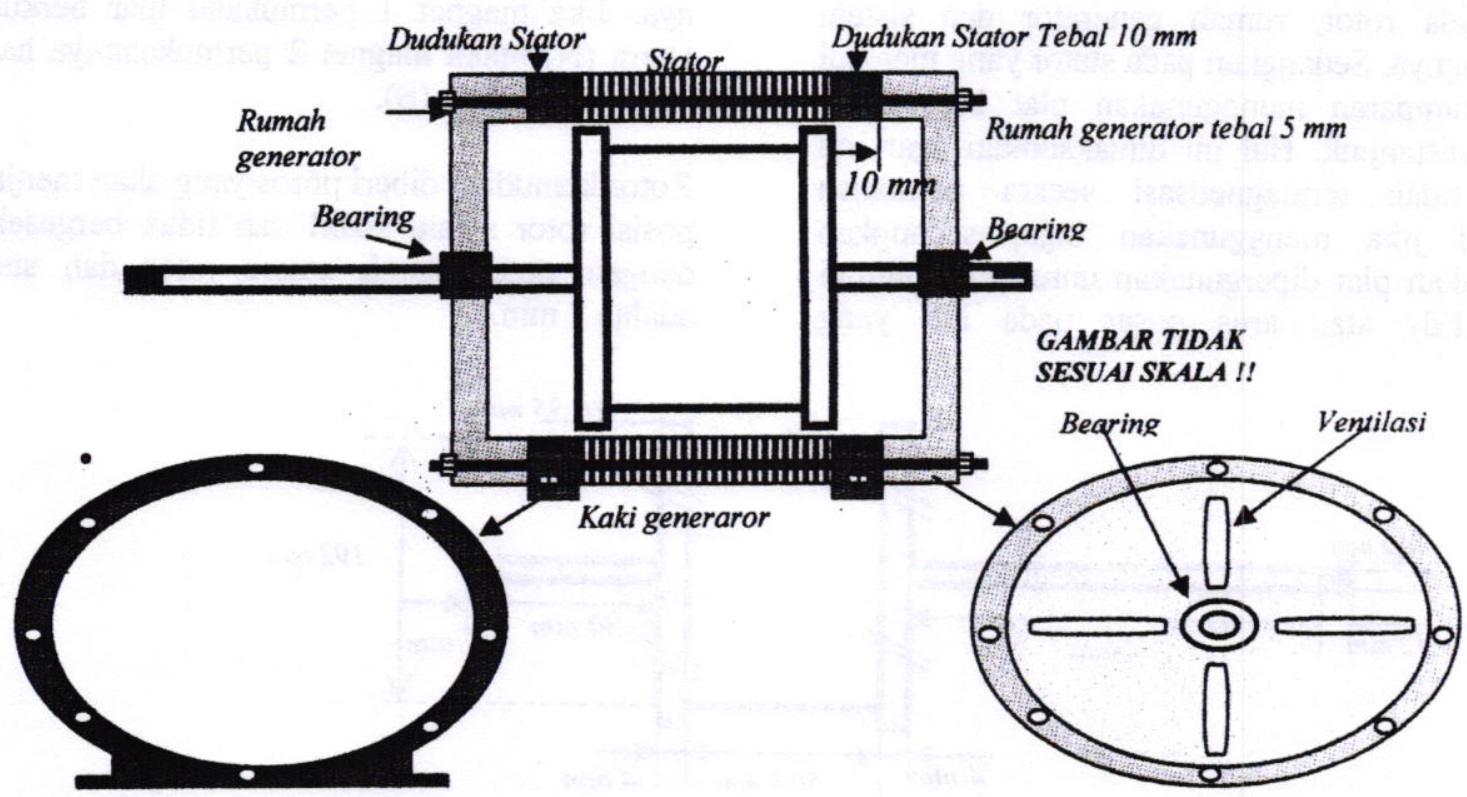

Gambar 3. Rancangan Rumah Generator 
memiliki kemampuan menangani beban lebih baik karena terdapat pembagian arus pada setiap fasanya;

$\checkmark$ mudah direparasi jika terdapat kerusakan.

Akan tetapi alasan utama pemilihan jumlah pole sebanyak 18 adalah untuk membuat selisih jumlah pole dengan rotor yang jumlahnya 22 . Ini dimaksudkan agar tidak pernah terjadi kondisi dimana pole pada rotor berpasangan satu satu dengan pole pada stator, khususnya pada kondisi diam. Keadaan dimana masing-masing pole saling berpasangan satu-satu akan menjadikan magnet pada rotor mengunci ke rotor dengan sangat kuat sehingga sulit diputar (distarter).

\section{PEMILIHAN KUMPARAN PADA STATOR}

Dengan memasang kumparan pada stator, menjadikan konstruksi dari genarator sangat kuat. Hal terpenting yang diperoleh dari konstruksi ini adalah tidak diperlukannya sikat (brushless) sehingga mengurangi bagian yang paling sering aus. Tegangan listrik yang demikian dapat disadap langsung ke kumparan sehingga konstruksi menjadi sederhana.

\section{KONSTRUKSI GENERATOR}

Secara keseluruhan generator dibangun dengan menggunakan bahan metal khususnya baja ST 37 pada rotor, rumah generator dan sistem bearingnya. Sedangkan pada stator yang menjadi inti kumparan menggunakan plat besi lunak yang ditumpuk. Hal ini dimaksudkan agar inti besi tidak termagnetisasi secara permanen seperti jika menggunakan baja, sedangkan tumpukan plat dipergunakan untuk mengurangi arus Edy atau arus pusar pada inti yang disebabkan induksi dan menyebabkan inti menjadi sangat panas.

Rumah generator berfungsi untuk menjaga sistem bearing tetap berada pada tempatnya sekaligus memberikan dudukan pada generator agar dapat dipasang stabil pada landasan.

Dudukan rumah generator sekaligus menjadi rangka yang menjepit tumpukan inti kumparan pada stator. Garis tengah dari generator dengan jumlah pole 18 pada stator dan 22 pada rotor adalah $270 \mathrm{~mm}$. ukuran ini masih dianggap moderat dan mudah diinstalasikan pada turbin angin ukuran sedang (blade 1,5 m).

\section{ROTOR}

Rotor merupakan bagian berputar sekaligus tempat magnet diletakkan. Dengan demikian konstruksinya harus sangat kuat, dan utamanya harus imbang (balans) sehingga mudah diputar, konstruksinya diperlihatkan pada Gambar 4 dan 5 .

Diameter terluar dari rotor adalah $192 \mathrm{~mm}$, dengan demikian dapat menampung 11 pasang magnet selebar 25,4 mm sebanyak 22 magnet.

Pemasangan magnet dilakukan dengan menempelkan pada permukaan rotor dengan permukaan magnet berselang-seling arah kutubnya. Jika magnet 1 permukaan luar berkutub Utara $(\mathrm{N})$ maka magnet 2 permukaannya harus berkutub Selatan (S).

Rotor kemudian diberi poros yang akan menjaga posisi rotor selalu stabil dan tidak bergesekan dengan stator. Jarak antara rotor dan stator adalah $2 \mathrm{~mm}$.

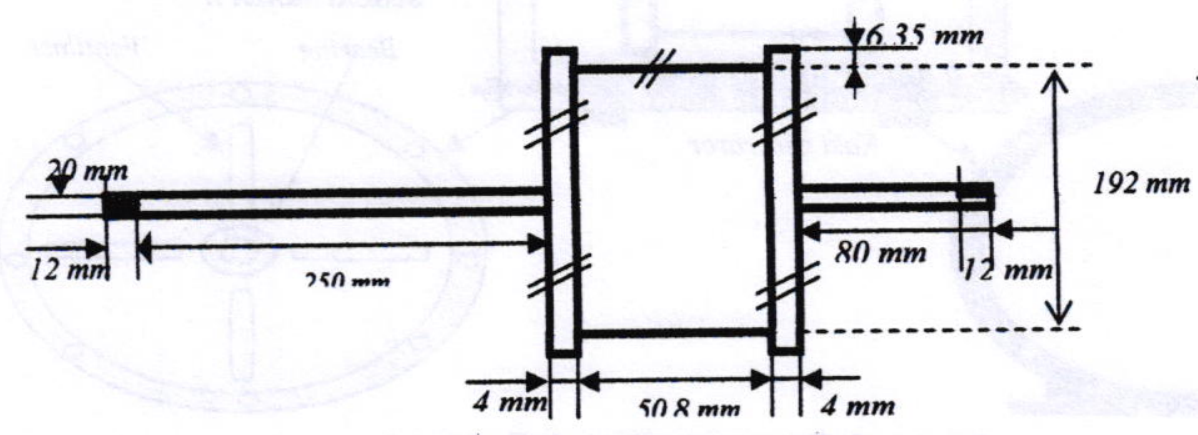

Gambar 4. Dimensi Rotor 


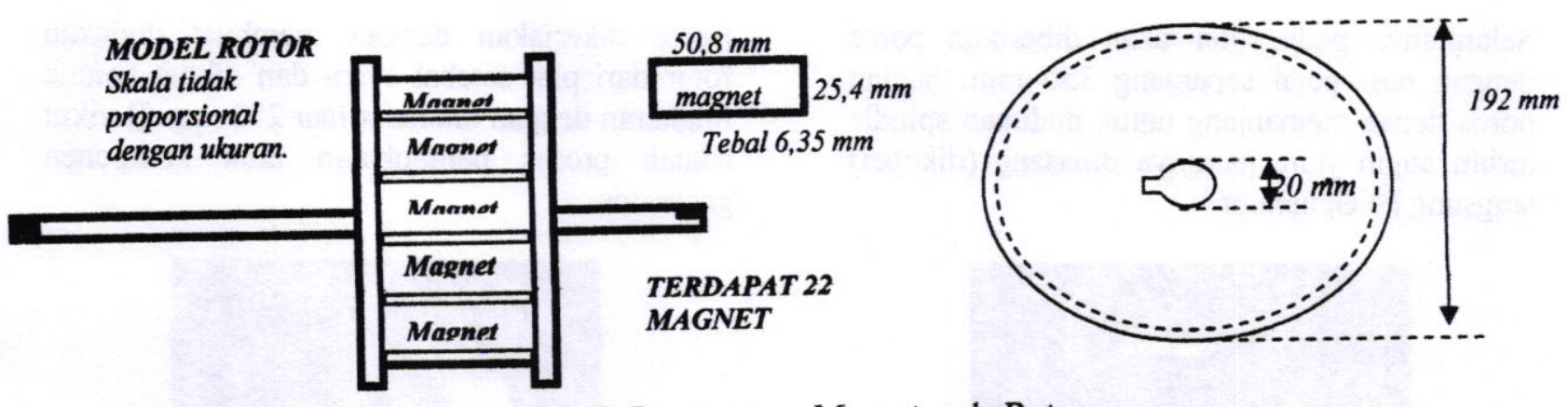

Gambar 5. Pemasangan Magnet pada Rotor

\section{KONSTRUKSI STATOR}

Stator merupakan inti magnetik dari kumparan utama generator penghasil listrik. Karena merupakan inti magnetik maka harus dibuat dari bahan feromagnetik yang yang secara fisik kurang kuat dibanding dengan bahan baja. Oleh karenanya harus diperkuat dengan dudukan. Konstruksi dari Stator diperlihatkan pada
Pada stator terdapat kutub yang menonjol yang berfungsi sebagai inti dari kumparan utama sebanyak 18 buah. Masing-masing kutub dirancang mampu menampung sampai 525 belitan kawat email dengan diameter $0,5 \mathrm{~mm}$. Tumpukan dari plat inti pada rotor disusun sehingga setebal panjang magnet $50,8 \mathrm{~mm}$.

Gambar 6.

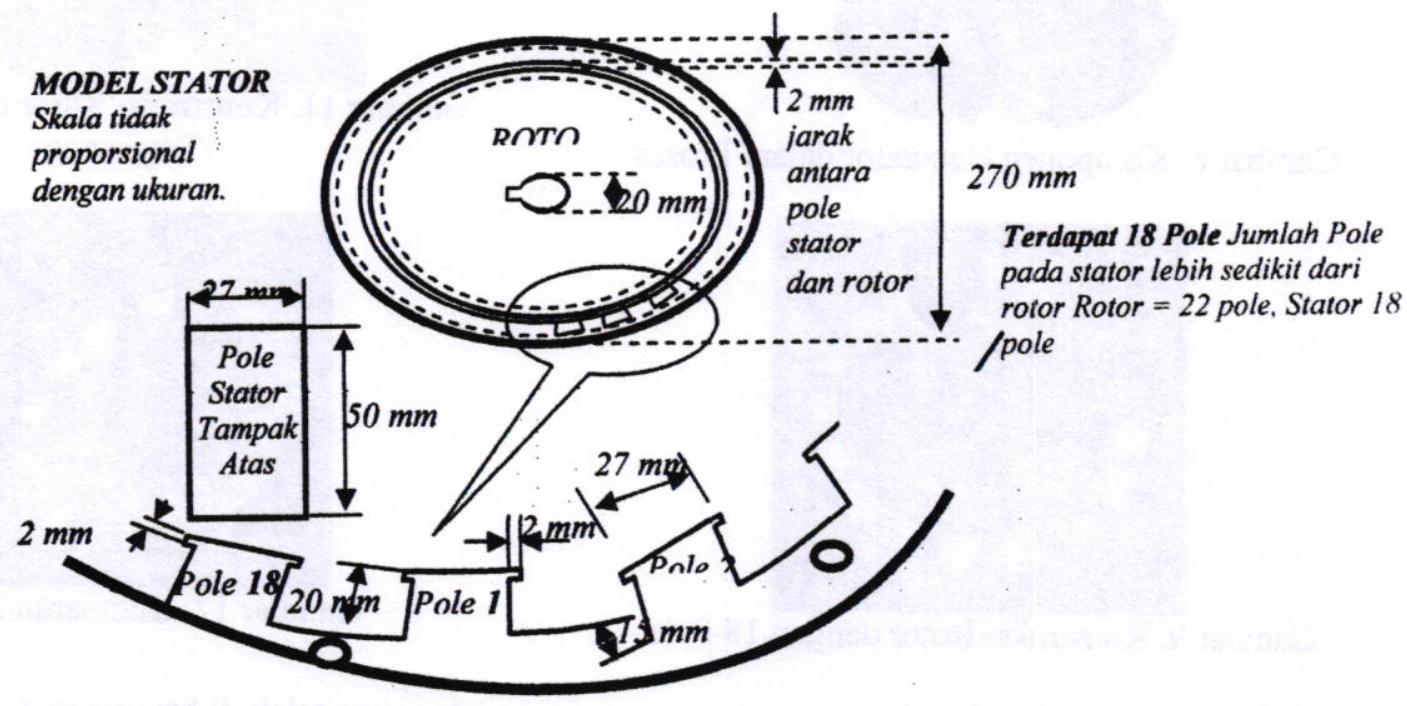

Gambar 6. Rancangan Stator

\section{PEKERJAAN METAL GENERATOR}

Pembuatan generator menggunaan bahan baja dan besi oleh karenanya diperlukan penanganan khusus yakni dilakukan dengan pembubutan sesuai dengan gambar rencana. Proses pembubutan rotor dilakukan dengan menggunakan bahan dari baja yang terdiri dari tiga komponen. Pada bagian tengah dibuat dari silinder prefab yang ukuran diameternya $20 \mathrm{~cm}$ dan dibubut menjadi $190 \mathrm{~mm}$. bagian tengah ini dipergunakan untuk menempelkan magnet permanen. Selanjutnya dibuat tepian kiri dan kanan dari plat baja. Untuk menghubungkan ketiganya dipergunakan baut. $\mathrm{Hal}$ ini akan memudahkan bila pada suatu saat diperlukan modifikasi terhadap konstruiksi rotor. 
Selanjutnya pada rotor akan diberikan poros dengan besi pejal sepanjang $350 \mathrm{~mm}$. bagian poros depan memanjang untuk dudukan spindle turbin angin yang nantinya dipasang (dikopel) langsung ke Generator.

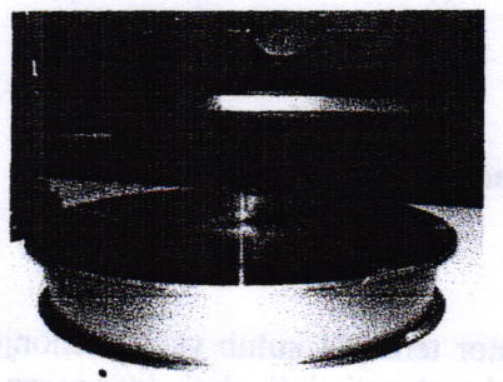

Gambar 7. Proses Pembubutan Rotor

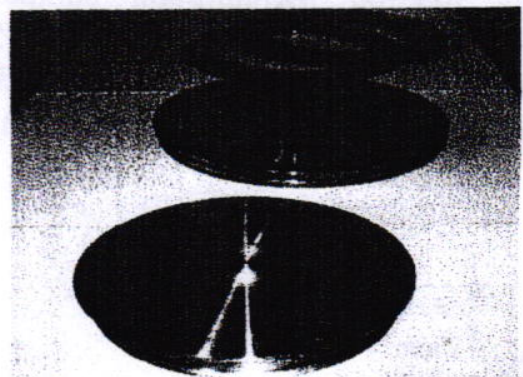

Gambar 8. Komponen Generator dalam Proses

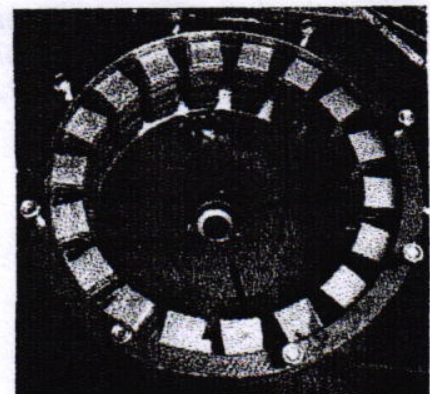

Gambar 9. Konstruksi Rotor dengan 18 Pole

Pada Gambar 9. diperlihatkan susunan rotor yang belum diberi kumparan arus. Nampak bahwa jumlah pole untuk kumparan berjumlah 18 buah. Gambar 10. memperlihatkan konstruksi rotor yang sebagai dudukan magnet dengan bearing kerucut. Pemilihan jenis bearing kerucut memberikan kekuatan pada poros rotor pada saat nantinya dikopel dengan hub turbin angin. Poros kerucut juga memberikan penahan pada poros agar tidak terdorong ke belakang maupun ke depan pada saat dibebani. Selanjutnya pada Gambar 11. memperihatkan
Rotor dikerjakan dengan membuat dudukan rotor dari plat setebal $1 \mathrm{~cm}$ dan dibuat bentuk lingkaran dengan diameter luar $270 \mathrm{~mm}$. Berikut adalah proses pembubutan utuk komponen generator.

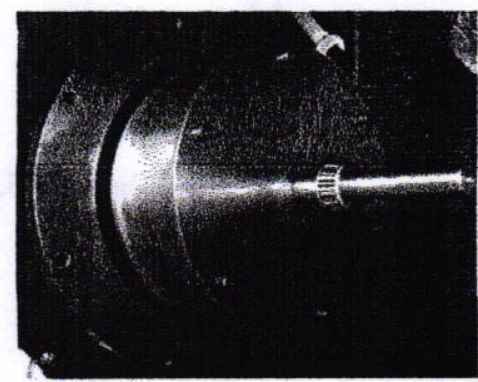

Gambar 10. Konstruksi Rotor dengan Bearing Kerucut

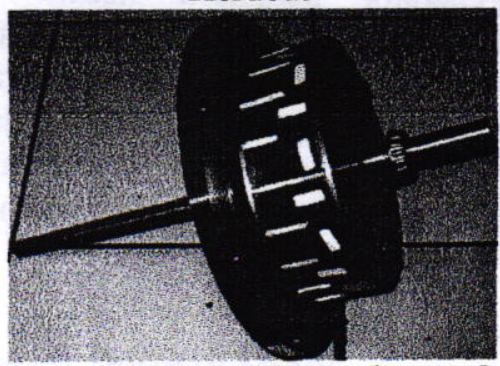

Gambar 11. Konstruksi Rotor dengan Magnet Terpasang

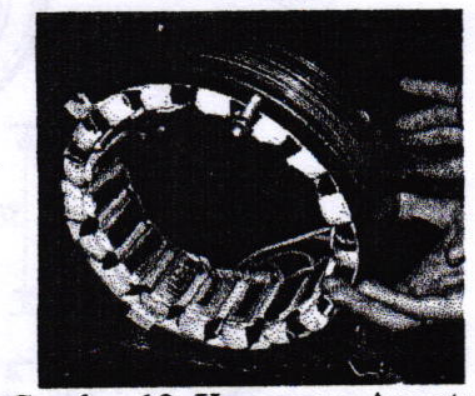

Gambar 12. Kumparan Armatur

rotor yang telah di beri magnet. Susunan magnet berjumlah 20 dengan permukaan kutubnya dibuat bergantian antara kutub utara dan selatan. Pada Gambar 12, memperlihatkan armature atau bagian stator yang telah diberi belitan kumparan kawat email dengan garis tengah $0,5 \mathrm{~mm}$. Penggunaan kawat berdiameter lebih kecil dimaksudkan untuk mendapatkan jumlah belitan sampai 500 kumparan setiap pole (kutub). Terdapat 18 kutub yang terdiri dari 3 fasa kumparan sehingga masing masing terdapat 6 kutub untuk setiap fasanya. Dengan jumlah 
belitan $500 \times 6=3000$ belitan untuk setiap fasa diperoleh resistasi dalam sebesar $40 \mathrm{Ohm}$.

\section{PENGUKURAN DAN ANALISIS DATA}

Generator yang telah selesai konstruksinya dilakukan pengujian dan pengukuran variabel kelistrikannya untuk mengetahui karakteristik dan kinerja teknisnya. Pengukuran pertama dilakukan untuk mendapatkan nilai resistansi dalam setiap kumparan pada ketiga fasa armature generator. Dengan menggunakan ohmmeter, terukur masing masing fasa memiliki resistansi dalam sebesar $40 \mathrm{Ohm}$.

Pengujian selanjutnya dilakukan untuk generator dalam kondisi dinamis dengan rangkaian sebagai berikut.

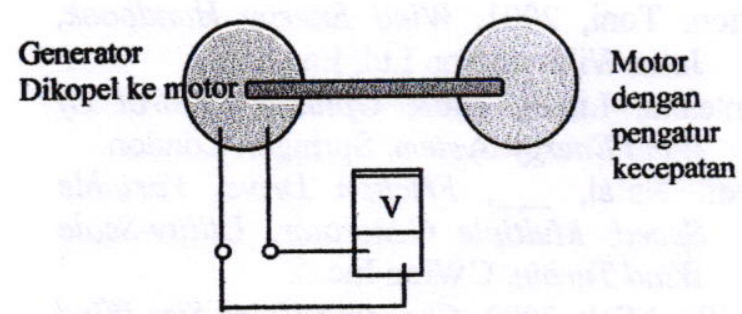

Gambar 13. Pengukuran Tegangan Generator Tanpa Beban

Generator dikopel secara mekanis ke motor dengan kecepatan putarannyayang dapat diatur. Dalam kondisi tanpa beban elektris pada generator, pada setiap fasa dilakukan pengukuran tegangan terbuka. Diambil data untuk 7 putaran dari kecepatan minimal sampai kecepatan nominal yakni $300 \mathrm{rpm}$.

Tabel 1. Hasil uji tegangan generator tanpa

\begin{tabular}{|l|l|l|}
\hline \multicolumn{3}{|c|}{ beban } \\
\hline No & RPM & Volt ac \\
\hline $\mathbf{1}$ & 25 & 5,2 \\
\hline 2 & 50 & 10,3 \\
\hline 3 & 100 & 15,8 \\
\hline 4 & 150 & 25,3 \\
\hline 5 & 200 & 35,4 \\
\hline 6 & 250 & 41,2 \\
\hline 7 & 300 & 58,7 \\
\hline
\end{tabular}

Data dari hasil pengukuran tegangan terbuka memperlihatkan bahwa semakin besar rpm generator akan menghasilkan tegangan terbuka yang semakin besar. Karena pengukuran menggunakan voltmeter ac, maka pembacaan yang diperoleh adalah tegangan rms (root means square) sehingga dapat dipergunakan dalam perhitungan tegangan dc nantinya.

Selanjutnya dilakukan pengukuran dengan beban resistif murni sebesar $10 \mathrm{ohm}$. Pengukuran dilakukan untuk satu fasa, hal ini dimaksudkan agar tidak diperlukan penyearah terlebih dahulu. Susunan rangkaiannya adalah sebagai berikut:

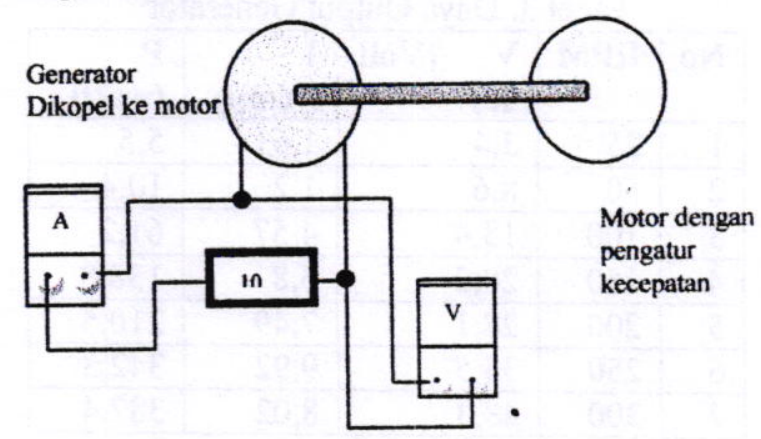

Gambar 14. Pengukuran Berbeban

Tabel 2. Hasil uji tegangan generator dengan beban

\begin{tabular}{|l|l|l|l|}
\hline No & RPM & Volt ac (V) & Amp (I) \\
\hline 1 & 25 & 3,4 & 1,61 \\
\hline 2 & 50 & 8,6 & 1,2 \\
\hline 3 & 100 & 13,4 & 4,57 \\
\hline 4 & 150 & 20,2 & 6,8 \\
\hline 5 & 200 & 28,1 & 7,49 \\
\hline 6 & 250 & 34,5 & 9,92 \\
\hline 7 & 300 & 48,3 & 8,02 \\
\hline
\end{tabular}

Dari data di atas dapat dilakukan analisis tegangan output dibandingkan dengan data pengukuran tanpa beban. Tegangan pada pengukuran berbeban menjadi lebih rendah dibanding tanpa beban, hal ini dikarenakan pada generator terdapat resistansi dalam yang mempengaruhi resistansi tertutup total dari rangkaian. Resistansi beban dan resistansi dari kumparan generator membentuk rangkaian seri sehingga terjadi pembagian tegangan. Hal ini 
yang menyebabkan pengukuran tegangan pada kondisi berbeban menjadi menurun. Pengukuran juga memperlihatkan bahwa arus yang mengalir pada beban meningkat sesuai dengan peningkatan rpm generator.

Dengan menggunakan persamaan daya $(\mathrm{P}=\mathrm{V} . \mathrm{I}$ watt), dapat dihitung daya output generator dalam kondisi berbeban. Maka pada rpm 25 diperoleh hasil, $P=3,4 \times 1,61=5,5$ watt Dengan menggunakan perhitungan seperti di atas, maka disusun tabel daya output generator sebagai berikut

Tabel 3. Daya Output Generator

\begin{tabular}{|c|c|c|c|c|}
\hline No & RPM & $\begin{array}{ll} & \text { (Volt } \\
\text { ac) }\end{array}$ & $\begin{array}{l}\text { I } \\
\text { (Amp) }\end{array}$ & $\begin{array}{l}\text { P } \\
\text { (watt) }\end{array}$ \\
\hline 1 & 25 & 3,4 & 1,61 & 5,5 \\
\hline 2 & 50 & 8,6 & 1,2 & 10,4 \\
\hline 3 & 100 & 13,4 & 4,57 & 61,2 \\
\hline 4 & 150 & 20,2 & 6,8 & 138,8 \\
\hline 5 & 200 & 28,1 & 7,49 & 210,5 \\
\hline 6 & 250 & 34,5 & 9,92 & 342,3 \\
\hline$\frac{0}{7}$ & 300 & 48,3 & 8,02 & 387,4 \\
\hline
\end{tabular}

Dari tabel di åtas diperlihatkan bahwa daya output meningkat semakin pesat pada rpm semakin tinggi. Hal ini memberikan indikasi bahwa generator akan bekerja semakin efesien pada putaran semakin tinggi.

\section{KESIMPULAN}

Merujuk pada hasil penelitian ini, dapat diambil kesimpulan penting yang relevan diantaranya:

a. Generator Low RPM dapat dibuat dengan menggunakan rotor multipole yang terdiri dari 20 magnet untuk menghasilkan daya listrik 387,4 watt pada beban $10 \mathrm{ohm}$ pada putaran $300 \mathrm{rpm}$. b. Tegangan yang dihasilkan adalah 48,3 volt dengan arus listrik 8,3 ampere dengan membuat armature dimana setiap polenya dibuat dari 500 belitan atau keseluruhan fasa adalah $6 \times 500$ belitan kawat $0,5 \mathrm{~mm}$ dengan resistansi dalam sebesar $40 \mathrm{ohm}$ dan berputar pada kecepatan $300 \mathrm{rpm}$.

c. Pada kecepatan putar semakin tinggi, generator memperlihatkan perilaku semakin efesien. Namun memiliki batas maksimal dikarenakan arus Eddy maupun kemampuan dari kawat kumparan untuk menghantarkan arus.

d. Untuk mendapatkan rpm yang semakin rendah, diperlukan jumlah pasangan kutub magnet yang semakin banyak.

\section{PUSTAKA}

Burton, Toni, 2001, Wind Energy Handbook, John Wiley \& Son Ltd, England.

Monteanu, Iulian, 2008, Optimal Control Of Wind Energy System, Springer, London.

Nayef, Na'al, _, Friction Drive, Variable Speed, Multiple Generator, Utility-Scale Wind Turbin, CWind Inc.

Sagrillo, Mick, 2002, Choosing Home Size Wind Generator, Home Power.

Noel, John M, _ Frech Wind Generator System, Aerowatt Corp., Paris, France.

Caterpillar_2005, Generator Systems, Application and Installation Guide

Unnewehr, L.E., and S.A. Nasar. Electric Vehicle Technology.New York: John Willey \& Sons, 1982.

Rashid, Muhammad H. Power Electronics: Circuits, Devices, and Applications 2nd edition. New Jersey: Prentice Hall, 1993. 